\title{
Identification of Brassinosteroids with Epimerized Substituents and / or the 23-Oxo Group in Pollen and Anthers of Japanese Cedar
}

\author{
Takao Yokota, ${ }^{1, \dagger}$ Kyoko Higuchi, ${ }^{2}$ Nobutaka TAKahashi, ${ }^{2}$ Yasuo Kamuro, ${ }^{3}$ \\ Tsuyoshi Watanabe, ${ }^{4}$ and Suguru TaKatsuto ${ }^{5}$ \\ ${ }^{1}$ Department of Biosciences, Teikyo University, Utsunomiya 320, Japan \\ ${ }^{2}$ Department of Agricultural Chemistry, The University of Tokyo, Bunkyo-ku, Tokyo 113, Japan \\ ${ }^{3}$ BAL Planning Co. Ltd., 2-15-16 Hanaike, Ichinomiya-shi, Aichi 491, Japan \\ ${ }^{4}$ Tama Biochemical Co. Ltd., 2-7-1 Nishishinjuku, Shinjuku-ku, Tokyo 163, Japan \\ ${ }^{5}$ Department of Chemistry, Joetsu University of Education, Joetsu-shi, Niigata 943, Japan
}

Received September 12, 1997

Brassinosteroids in Japanese cedar (Cryptomeria japonica) were analyzed by GC-MS after being purified by reversed-phase HPLC. The occurrence of four stereoisomers of 23-dehydrobrassinolide, three stereoisomers of 28-homobrassinolide, and an isomer of homodolicholide was revealed. The stereochemical structures of these brassinosteroids remain undetermined. Among these, the 23-dehydrobrassinolide stereoisomers are the first brassinosteroids identified with an oxo group located at the C23 position. In addition, known brassinosteroids 3-dehydroteasterone, typhasterol and dolicholide were identified.

Key words: Cryptomeria japonica; 23-dehydrobrassinolide; 28-homobrassinolide; dolicholide; 28-homodolicholide

Brassinosteroids (BRs) constitute a new class of plant growth regulators occurring in higher and lower plants that show a broad spectrum of physiological activities and also anti-stress activity. ${ }^{1-4)}$ Recent advances in biosynthetic studies on BRs, ${ }^{5-8)}$ as well as new findings in biochemistry and molecular genetics with BR mutants, ${ }^{9-13)}$ have confirmed that BRs are plant hormones governing many aspects of plant growth, especially cell elongation. These findings have been recently reviewed. ${ }^{14-16)}$ Brassinosteroids seem to play an important role in pollen tissue, because among known plant hormones, BRs are the most potent promoters of pollen tube elongation $^{17)}$ and BR-deficient or insensitive mutants of Arabidopsis thaliana ${ }^{9-12)}$ have reduced male fertility. Among various tissues hitherto examined, pollen has been found to be the richest source of BRs as seen, for example, in Brassica napus, ${ }^{18)}$ Japanese black pine ( $P$ inus thunbergii) ${ }^{19)}$ and Arizona cypress (Cupressus arizonica). ${ }^{20)}$ Thus, it may be useful to analyze the endogenous BRs in pollen for elucidating the biosynthesis, metabolism and role of BRs.

This paper describes the identification and structural determination of endogenous BRs contained in the pollen and anthers of Japanese cedar (Cryptomeria

\section{japonica).}

\section{Materials and Methods}

Plant materials. The pollen and anthers of Japanese cedar (Cryptomeria japonica D. Don) were collected at the foot of Mt. Namba, Joetsu-shi, Niigata Prefecture, Japan.

Bioassay. The rice lamina inclination test was carried out on etiolated seedlings of rice according to the reported method. ${ }^{21)}$

Extraction. The pollen and anthers of $C$. japonica $(3.0 \mathrm{~kg})$ were extracted with $\mathrm{MeOH}$ for a week and then with EtOAc-MeOH (1:1) for a further week. The organic extract was filtered and, after the solvent had been evaporated, was subjected to partitioning three times between water and EtOAc. The EtOAc phases were combined, evaporated and then partitioned between nhexane and $90 \% \mathrm{MeOH}$. The n-hexane phase was washed twice with $90 \% \mathrm{MeOH}$, while the aqueous $\mathrm{MeOH}$ phases were combined and concentrated. The residue obtained was mixed with aq. $\mathrm{NaHCO}_{3}$ and extracted twice with EtOAc, the combined EtOAc phases then being concentrated to give an oil (60 g).

Purification of BRs. The afore-mentioned oil was divided into two portions which were separately purified on a column of silica gel $(4.5 \mathrm{~cm}$ i.d. $\times 34 \mathrm{~cm}$, Kieselgel 60, 70-230 mesh, Merck, Darmstadt, Germany). Elution was carried out stepwise with $500 \mathrm{ml}$ each of $0,2.5$, $5,10,20$, and $100 \% \mathrm{MeOH}$ in $\mathrm{CHCl}_{3}$. The eluates with $10-20 \% \mathrm{MeOH}$ in $\mathrm{CHCl}_{3}$ were active and were combined to give an active fraction $(20 \mathrm{~g})$ which was further purified on a column of silica gel $(3.5 \mathrm{~cm}$ i.d. $\times 40 \mathrm{~cm})$. Elution was carried out stepwise with $600 \mathrm{ml}$ each of 1 , $2,3,4,5,6,7,8,10,15$, and $20 \% \mathrm{MeOH}$ in $\mathrm{CHCl}_{3}$, the eluates being collected in $200-\mathrm{ml}$ fractions. The active fractions eluted with $4-6 \%$ and $8 \% \mathrm{MeOH}$ in $\mathrm{CHCl}_{3}$ were combined to give an oil (2.3 g). This was extracted with $60 \% \mathrm{MeOH}$ in $\mathrm{H}_{2} \mathrm{O}$, and the extract was chro-

\footnotetext{
$\dagger$ To whom correspondence should be addressed.

Abbreviations: BR, brassinosteroid; GC-MS, gas chromatography-mass spectrometry; HPLC, high-performance liquid chromatography; tR, retention time.
} 
matographed on charcoal ( $20 \mathrm{~g}, 230-400$ mesh, Nacalai Co., Kyoto, Japan). Elution was carried out stepwise with $500 \mathrm{ml}$ each of 60,80 and $90 \% \mathrm{MeOH}$ in $\mathrm{H}_{2} \mathrm{O}$, $100 \% \mathrm{MeOH}$, and 90,70 and $50 \% \mathrm{MeOH}$ in $\mathrm{CHCl}_{3}$. The eluates with 70 and $50 \% \mathrm{MeOH}$ in $\mathrm{CHCl}_{3}$ were combined and concentrated to give an active oil $(0.6 \mathrm{~g})$ which was applied to a column of Sephadex LH-20 (26.6 mm i.d. $\times 90 \mathrm{~cm}$, Pharmacia Fine Chemicals, Uppsala, Sweden). Elution was done with $\mathrm{CHCl}_{3}-\mathrm{MeOH}$ (1:4) at a flow rate of $0.5 \mathrm{ml} / \mathrm{min}$, and each fraction was collected in $10-\mathrm{ml}$ amounts. The active fractions were eluted between 330-360 ml, and rechromatographed on a Sephadex LH-20 column $(26.6 \mathrm{~mm}$ i.d. $\times 90 \mathrm{~cm})$, using $70 \% \mathrm{MeOH}$ in $\mathrm{H}_{2} \mathrm{O}$ as the mobile phase. Activity was eluted between 430 and $600 \mathrm{ml}$ and in the further methanol washing $(500 \mathrm{ml})$. The active eluates were collected to give an active fraction $(90 \mathrm{mg})$.

HPLC. The active fraction was further purified on a column of Senshu Pak ODS 3251-D $(8 \times 250 \mathrm{~mm})$ at $40^{\circ} \mathrm{C}$. The mobile phase was $45 \% \mathrm{MeCN}$ for the first 40 min and $80 \% \mathrm{MeCN}$ for a further $25 \mathrm{~min}$ at a flow rate of $2 \mathrm{ml} / \mathrm{min}$, fractions being collected every minute. Active fractions $11-30$ and 47-62 were separately combined because of the unsatisfactory separation and were termed fraction I and II, respectively. These were dissolved in $\mathrm{MeOH}$ and passed through a short column of diethylaminopropyl silica Bondesil (Analytical International, Harbor City, CA., U.S.A.) and then purified again with the same, but freshly packed, ODS column. Fraction I was purified with $45 \% \mathrm{MeCN}$ as the mobile phase at a flow rate of $2 \mathrm{ml} / \mathrm{min}$, the eluted fractions being collected every minute. Major activity was found in fractions $14,19 / 20,22 / 23$, and $25 / 26$. Fraction II was similarly purified with $70 \% \mathrm{MeCN}$ as the mobile phase to show major activity in fractions 15/16.

Synthesis of 24-epi-23-dehydrobrassinolide (15). A known 24-epibrassinolide 2,3-diacetate ${ }^{22)}(\mathbf{1 2}, 72.7 \mathrm{mg}$, $0.129 \mathrm{mmol}$ ) was partially acetylated with acetyl chloride $(13 \mathrm{mg}, 0.166 \mathrm{mmol})$ and pyridine $(10 \mathrm{ml})$ at $0^{\circ} \mathrm{C}$ to room temperature overnight. Work-up (EtOAc) and subsequent chromatography on silica gel $(1.0 \mathrm{~cm}$ i.d. $\times 20 \mathrm{~cm})$, eluting with toluene-EtOAc $(20: 1)$ gave 24-epibrassinolide 2,3,22-triacetate (13, $23 \mathrm{mg}, 29.4 \%$ ), Rf 0.45 (toluene-EtOAc, $1: 1$ ). This was dissolved in acetone $(10 \mathrm{ml})$ and treated with Jones reagent $(0.2 \mathrm{ml})$ at -5 to $0^{\circ} \mathrm{C}$ for $2 \mathrm{hr}$. Work-up (EtOAc) provided 24-epi23-dehydrobrassinolide 2,3,22-triacetate (14, $22.2 \mathrm{mg}$, $96.8 \%$ ), Rf 0.53 (toluene-EtOAc, 1:1), ${ }^{1} \mathrm{H}-\mathrm{NMR}$ $\left(\mathrm{CDCl}_{3}\right) \delta: 0.78(3 \mathrm{H}, \mathrm{s}), 0.89(3 \mathrm{H}, \mathrm{d}, J=8 \mathrm{~Hz}), 1.02$ $(3 \mathrm{H}, \mathrm{s}), 2.01(3 \mathrm{H}, \mathrm{s}), 2.11(3 \mathrm{H}, \mathrm{s}), 2.16(3 \mathrm{H}, \mathrm{s}), 2.30$ $(1 \mathrm{H}, \mathrm{m}), 2.49(1 \mathrm{H}, \mathrm{m}), 3.00(1 \mathrm{H}$, double $\mathrm{d}, J=4$ and 11 $\mathrm{Hz}), 4.09(2 \mathrm{H}, \mathrm{m}), 4.86(1 \mathrm{H}, \mathrm{m}), 5.21(1 \mathrm{H}, \mathrm{m}), 5.38$ $(1 \mathrm{H}, \mathrm{m})$.

A mixture of $14(22.2 \mathrm{mg}, 0.0368 \mathrm{mmol})$ and $\mathrm{Na}_{2} \mathrm{CO}_{3}$ $(0.10 \mathrm{~g})$ in $\mathrm{MeOH}(8 \mathrm{ml})$ and water $(2 \mathrm{ml})$ was heated at $50-80^{\circ} \mathrm{C}$ for $1 \mathrm{hr}$. The reaction mixture was cooled and then acidified with acetic acid $(1 \mathrm{ml})$. Work-up $\left(\mathrm{CHCl}_{3}\right)$ and chromatography on silica gel $(1.0 \mathrm{~cm}$ i.d. $\times 20 \mathrm{~cm})$, eluting with $\mathrm{CHCl}_{3}-\mathrm{MeOH}(97: 3)$, afforded $15(8.9 \mathrm{mg}$,
$50.6 \%)$, Rf $0.33\left(\mathrm{CHCl}_{3}-\mathrm{MeOH}, 9: 1\right)$, FD-MS $m / z$ (rel. int.): $479\left(\mathrm{M}^{+}+1,15 \%\right), 379$ (12), 99 (100). ${ }^{1} \mathrm{H}-\mathrm{NMR}$ $\left(\mathrm{CDCl}_{3}\right) \delta_{\mathrm{H}}: 0.72(3 \mathrm{H}, \mathrm{d}, J=7 \mathrm{~Hz}), 0.76(3 \mathrm{H}, \mathrm{s}), 0.88$ $(3 \mathrm{H}, \mathrm{d}, J=7 \mathrm{~Hz}), 0.92(3 \mathrm{H}, \mathrm{d}, J=7 \mathrm{~Hz}), 0.93(3 \mathrm{H}, \mathrm{s})$, $1.03(3 \mathrm{H}, \mathrm{d}, J=7 \mathrm{~Hz}), 2.53(1 \mathrm{H}$, quintet, $J=7 \mathrm{~Hz}, 24$ $\mathrm{H}), 3.12(1 \mathrm{H}$, double d, $J=4.5,12 \mathrm{~Hz}, 5-\mathrm{H}), 3.48(1 \mathrm{H}$, $\mathrm{d}, J=5 \mathrm{~Hz}, \mathrm{OH}), 3.72(2 \mathrm{H}$, broad d, $J=11 \mathrm{~Hz}, 2-\mathrm{H})$, $4.03(1 \mathrm{H}$, broad, $3-\mathrm{H}), 4.10\left(2 \mathrm{H}, \mathrm{m}, 7-\mathrm{H}_{2}\right), 4.22(1 \mathrm{H}$, double d, $J=1.4,5 \mathrm{~Hz}, 22-\mathrm{H})$.

$G C-M S$. A JEOL 303 mass spectrometer equipped with a fused silica DB-1 capillary column $(0.25 \mathrm{~mm}$ i.d. $\times 15 \mathrm{~m}, 0.25 \mathrm{~mm}$ film thickness, J \& W Scientific, Folsom, CA., USA) was used in the electron impact mode $(70 \mathrm{eV})$. The carrier gas was helium at a flow rate of $1 \mathrm{ml} / \mathrm{min}$, the injection port temperature was $260^{\circ} \mathrm{C}$, and the samples were introduced by splitless injection (1.5 min sampling time). The column oven temperature was held at $170^{\circ} \mathrm{C}$ for $2 \mathrm{~min}$, before being elevated to $270^{\circ} \mathrm{C}$ at $32^{\circ} \mathrm{C} / \mathrm{min}$, and then to $290^{\circ} \mathrm{C}$ at $2^{\circ} \mathrm{C} / \mathrm{min}$. Methaneboronation was carried out by heating samples dissolved in pyridine containing methaneboronic acid $(2 \mathrm{mg} / \mathrm{ml})$ at $70^{\circ} \mathrm{C}$ for $30 \mathrm{~min} .^{23)}$ Further trimethylsilylation to obtain methaneboronate-trimethylsilyl ethers was carried out by adding bis(trimethylsilyl)acetamide to the foregoing reaction mixture and leaving the mixture at room temperature for $5 \mathrm{~min}$.

\section{Results}

The content of BRs in the pollen and anthers of $C$. japonica was determined by the rice lamina inclination test after being purified by charcoal chromatography to be $c a .10 \mu \mathrm{g}$ of brassinolide equivalent per $\mathrm{kg}$ fresh weight of the tissue. Through the first-stage purification, the endogenous BRs were separated into polar (I) and less-polar (II) fractions. Fractions I and II were purified by reversed-phase HPLC, resulting in the separation of active fractions (Fig. 1). These fractions were analyzed by GC-MS after being derivatized, revealing the presence of BRs shown in Table I, with the structures shown in Fig. 2.

Three known BRs, namely, 3-dehydroteasterone (1) and typhasterol (2) in fractions II-15/16, and dolicholide (3) in fraction I-14 were identified by fullscan mass spectra and retention times in comparison with authentic samples. Furthermore, three epimers of 28-homobrassinolide $(\mathbf{8}, 9$ and 10) were detected in fractions II-19/20, $-22 / 23$, and $-25 / 26$. Their mass spectra were indistinguishable from that of authentic 28homobrassinolide. However, their retention times were apparently shorter than that of the authentic compound (16.95 $\mathrm{min}$ ), indicating that the functional groups in these compounds were epimerized. Likewise, an epimer of 28-homodolicholide (11), which had a shorter retention time than the authentic 28-homodolicholide (17.40 min), was found in fraction $\mathrm{I}-22 / 23$. The positions for epimerization of these isomers remain undetermined.

In addition, four epimeric BRs (4, 5, 6 and 7) were detected in fractions $I-19 / 20,-22 / 23$ and $-25 / 26$. Careful examination of the total ion current traces, mass chromatograms and mass spectra revealed that, after being 
Table I. GC-MS Data on the Bismethaneboronates of Endogenous Brassinosteroids in Pollen and Anthers of Japanese Cedar

\begin{tabular}{|c|c|c|c|}
\hline $\begin{array}{l}\text { HPLC } \\
\text { fraction }\end{array}$ & Compound & $\begin{array}{c}\mathrm{GC}-\mathrm{tR} \\
(\mathrm{min})\end{array}$ & $\begin{array}{l}\text { GC-MS spectral data } \\
\text { Fragment ion } \mathrm{m} / \mathrm{z} \text { (relative intensity) }\end{array}$ \\
\hline $\mathrm{I}-14$ & 3 & 15.38 & $\begin{array}{l}526\left(\mathrm{M}^{+}, 23\right), 403(29), 385(17), 373(15), 357(5), \\
343(64), 153(73), 124(100), 82(99)\end{array}$ \\
\hline \multirow[t]{4}{*}{$\mathrm{I}-19 / 20$} & 4 & 13.85 & Spectrum of bismethaneboronate A in Fig. 4(b) \\
\hline & & 15.28 & Spectrum of bismethaneboronate B in Fig. 4(c) \\
\hline & & 15.82 & Spectrum of bismethaneboronate B in Fig. 4(c) \\
\hline & 8 & 16.80 & $\begin{array}{l}542\left(\mathrm{M}^{+}, 4\right), 457(14), 397(6), 374(51) \\
345(22), 177(47), 169(100)\end{array}$ \\
\hline \multirow[t]{8}{*}{$\mathrm{I}-22 / 23$} & 5 & 13.80 & Spectrum of bismethaneboronate A in Fig. 4(b) \\
\hline & & 15.10 & Spectrum of bismethaneboronate B in Fig. 4(c) \\
\hline & & 15.78 & Spectrum of bismethaneboronate B in Fig. 4(c) \\
\hline & 6 & 14.00 & Spectrum of bismethaneboronate A in Fig. 4(b) \\
\hline & & 15.33 & Spectrum of bismethaneboronate B in Fig. 4(c) \\
\hline & & 15.90 & Spectrum of bismethaneboronate B in Fig. 4(c) \\
\hline & 9 & 16.67 & $\begin{array}{l}542\left(\mathrm{M}^{+}, 4\right), 457(17), 397(8), 374(55) \\
345(24), 177(45), 169(100)\end{array}$ \\
\hline & 11 & 17.25 & $\begin{array}{l}540\left(\mathrm{M}^{+}, 5\right), 497(100), 427(10), 403(8), \\
385(13), 373(10), 343(26), 177(12), \\
167(80), 138(73), 96(58)\end{array}$ \\
\hline \multirow[t]{4}{*}{$\mathrm{I}-25 / 26$} & 7 & 13.80 & Spectrum of bismethaneboronate A in Fig. 4(b) \\
\hline & & 15.08 & Spectrum of bismethaneboronate B in Fig. 4(c) \\
\hline & & 15.73 & Spectrum of bismethaneboronate B in Fig. 4(c) \\
\hline & 10 & 16.70 & $\begin{array}{l}542\left(\mathrm{M}^{+}, 10\right), 457(16), 374(55), 346(22), \\
345(25), 344(29), 177(45), 169(100)\end{array}$ \\
\hline \multirow[t]{2}{*}{ II- $15 / 16$} & 2 & 11.93 & $\begin{array}{l}544\left(\mathrm{M}^{+}, 100\right), 529(50), 526(26), 515(89), \\
454(66), 155(39)\end{array}$ \\
\hline & 1 & 13.33 & $\begin{array}{l}470\left(\mathrm{M}^{+}, 35\right), 399(5), 339(3), 316(15) \\
287(4), 260(3), 245(9), 155(100)\end{array}$ \\
\hline
\end{tabular}

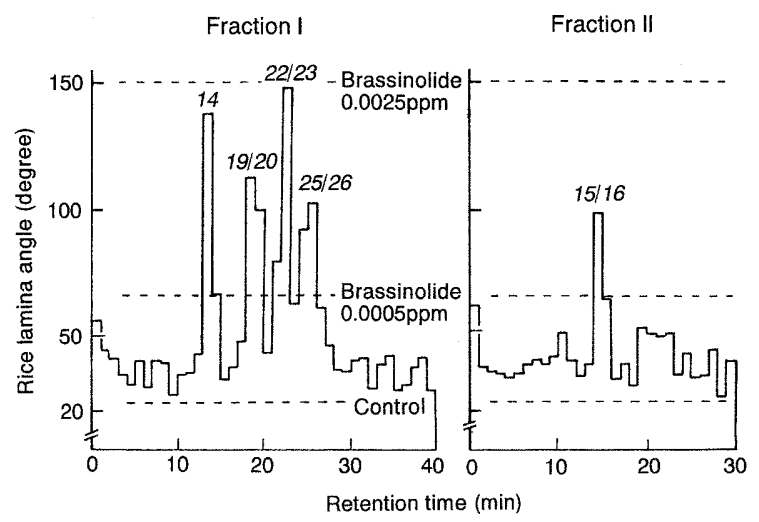

Fig. 1. Separation of Brassinosteroids in the Pollen and Anthers of Japanese Cedar by reversed-phase HPLC.

Fraction I (polar) and fraction II (less polar) that were obtained after pre-purifying the extract of Japanese cedar were chromatographed in an octadesylsilica column. Eluates equivalent to about $30 \mathrm{~g}$ fresh weight of tissue were dissolved in $20 \mathrm{ml}$ of water prior to the rice lamina inclination bioassay. Italic figures denote the number of fractions that were analyzed by GC-MS.

converted with methaneboronic acid, the respective BRs gave rise to two types of mass-spectrometrically indistinguishable derivatives, namely, bismethaneboronate $\mathrm{A}$ and an epimeric pair of bismethaneboronates B (Table I and Fig. 3). Bismethaneboronate A was always detected as the predominant product, indicating that it is a stable form. Bismethaneboronates $B$ of 4,5 and 6 were each found at a trace level, while those of 7 were each found at about one-third the level of bismethaneboronate A.

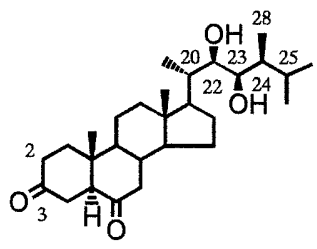

3-Dehydroteasterone (1)

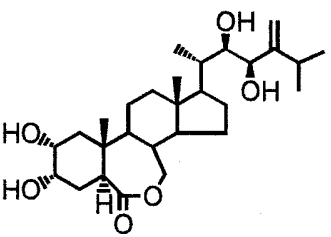

Dolicholide (3)<smiles>CCCC12CC34CC(O)C(O)CC3C(=O)OCC4C1CCC2C(C)C(O)C(O)C(C)CC</smiles>

$\xi$-epi-28-Homobrassinolide $(8,9$ and 10)

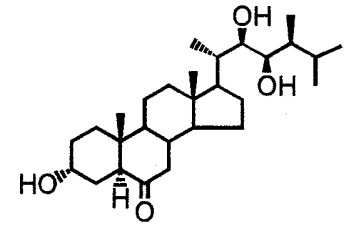

Typhasterol (2)<smiles>CC(C)C(C)C(=O)C(O)C(C)C1CCC2COC(=O)C3CC(O)C(O)CC23CC12CCC2</smiles>

$\xi$-epi-23-Dehydrobrassinolide $(4,5,6$ and 7$)$

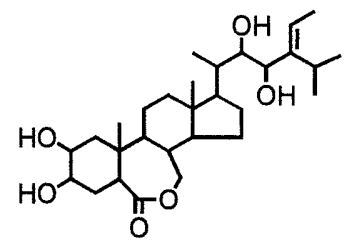

$\xi$-epi-28-Homodolicholide

(11)

Fig. 2. Structures of Brassinosteroids Found in the Pollen and Anthers of Japanese Cedar.

The stereochemistry of compounds $\mathbf{4 - 1 1}$ has not yet been determined. 


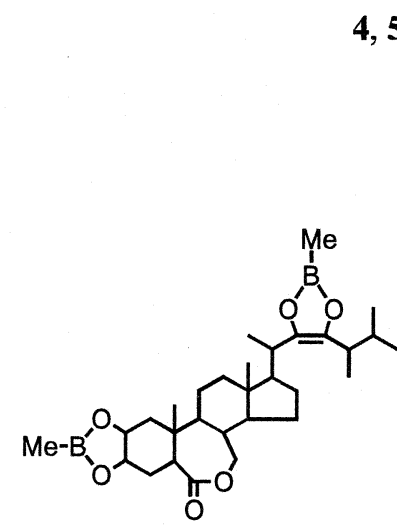

Bismethaneboronates A

\section{$4,5,6$ and 7}

$$
\begin{aligned}
& \mathrm{CH}_{3} \mathrm{BO}_{2} \mathrm{H}_{2} \\
& \text { pyridine } \\
& \text { Heating }
\end{aligned}
$$

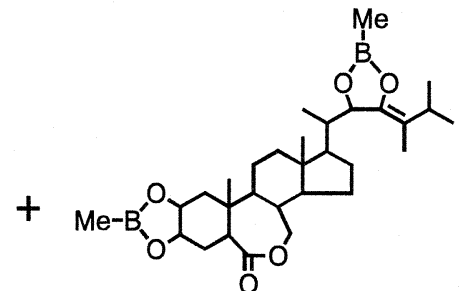

Fig. 3. Unusual Bismethaneboronate Derivatives of $\xi$-Epi-23-dehydrobrassinolides $(4,5,6$ and 7$)$.

The stereochemistry and double-bond geometry of the bismethaneboronate derivatives are not defined.

The amounts of bismethaneboronates B appeared to increase in proportion to the amount of the samples and the impurities contained.

The molecular ions of bismethaneboronates A and B were all observed at $m / z 526$ (Fig. 4). This molecular weight is the same as that of dolicholide (3) which has an additional double bond $\left(\Delta^{24(28)}\right)$ in the structure of brassinolide. Figure 4 compares the mass spectra of the bismethaneboronate derivatives of dolicholide (3) and $\xi$ epi-23-dehydrobrassinolide (7). Figure 5 shows the proposed fragmentation of these derivatives. The dolicholide bismethaneboronate gives rise to $\mathrm{m} / \mathrm{z} 373$ and 153 ions due to C20-C22 cleavage, $m / z 403$ and 124 ions due to $\mathrm{C} 22-\mathrm{C} 23$ cleavage, and a hydrocarbon ion of $\mathrm{m} / \mathrm{z} 82$ containing terminal 6 carbons of the side chain (Figs. 4(a) and 5(a)). As shown in Figs. 4(c) and 5(c), bismethaneboronates B lack ions due to $\mathrm{C} 22-\mathrm{C} 23$ cleavage as well as the $m / z 82$ ion, suggesting that the $\mathrm{C} 22-\mathrm{C} 23$ bond in bismethaneboronates B is stable, i.e. non-allylic. The fact that an ion at $m / z 153$ was predominant in bismethaneboronates $\mathrm{B}$ indicates that the $\mathrm{C} 20-\mathrm{C} 22$ bond is allylic and, hence, a double bond is located between $\mathrm{C} 23$ and C24. Thus, it is postulated that bismethaneboronates B are cyclic boronates of the C22 and C23 diol having one unsaturation at the C23(24) position (Fig. 3).

The fragmentation of bismethaneboronates $\mathrm{A}$ was quite different from that of bismethaneboronates $B$ (Figs. 4(b) and 5(b)). The pair of very strong ions at $\mathrm{m} / \mathrm{z}$ 483 (base peak) and $m / z 181$, which are considered to have arisen through cleavage of the C24-C25 and C17$\mathrm{C} 20$ bonds, respectively, are reminiscent of the presence of a double bond allylic to both of these bonds. Thus, bismethaneboronates $\mathrm{A}$ must have one unsaturation at the $\mathrm{C} 22$ (23) position, together with a cyclic boronate with the $\mathrm{C} 22$ and $\mathrm{C} 23$ diol group, thereby rationalizing the formation of the $\mathrm{m} / z 139$ and 111 ions as well.

The ene-diol structure in bismethaneboronates $\mathrm{A}$ and the enol moiety in bismethaneboronates B are unusual and are deemed to be artifacts accompanied by the derivatization. To satisfy these structures, compounds 4, 5, 6 and 7 must have a ketone group at C23, which would have been enolized during methaneboronation to afford a mixture of derivatives $\mathrm{A}$ and $\mathrm{B}$. Thus, these BRs were determined to be 23-dehydrobrassinolide and/or its stereoisomers (Fig. 2).

We synthesized one of the possible isomers, 24-epi-23dehydrobrassinolide (15). As shown in Fig. 6, 24epibrassinolide-2,3-diacetate (12) was partially acetylated to afford 24-epibrassinolide-2,3,22-triacetate (13), which was then oxidized with Jones reagent to give 24-epi-23-dehydrobrassinolide-2,3,22-triacetate (14). Saponification of 14 yielded 24-epi-23-dehydrobrassinolide (15). GC-MS analysis of 15 after methaneboro-
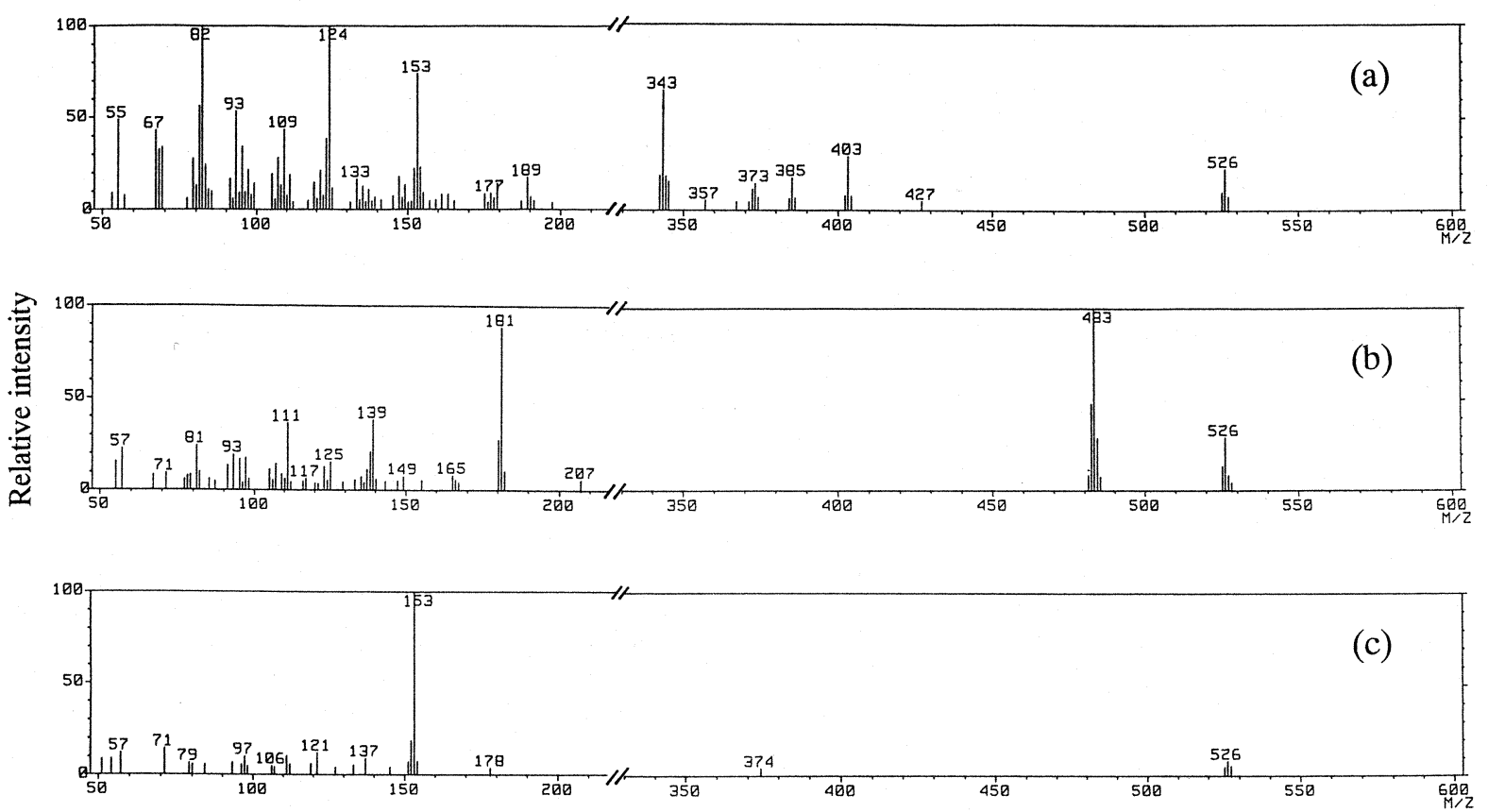

Fig. 4. Mass Spectra of Dolicholide (3) Bismethaneboronate (a) and $\xi$-Epi-23-dehydrobrassinolide (7) Bismethaneboronates A (b) and B (c). 

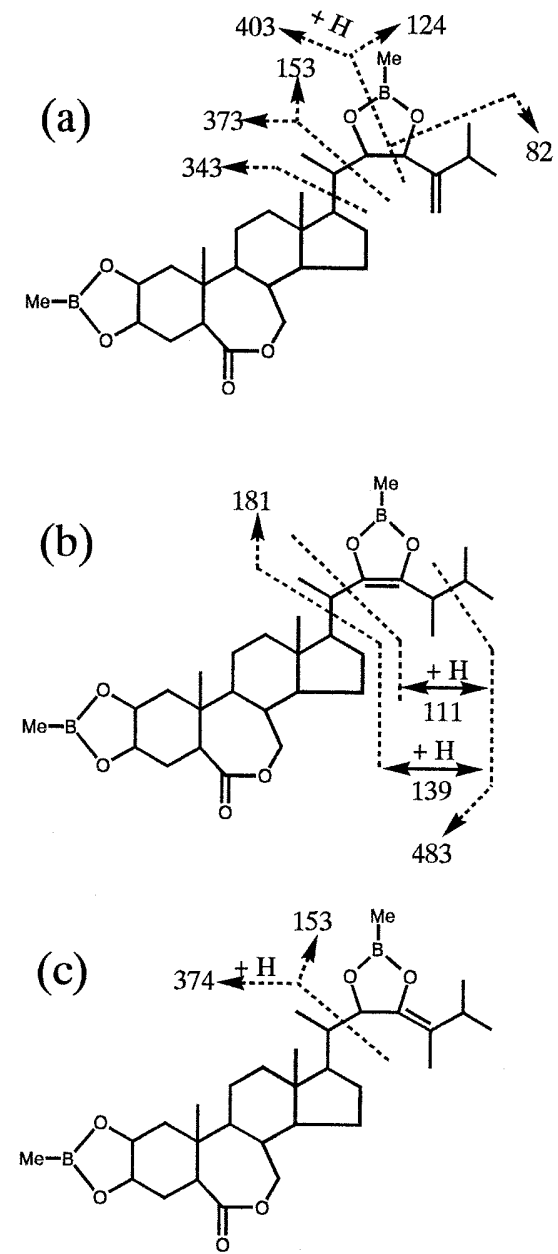

Fig. 5. Mass Fragmentation Proposed for Dolicholide Bismethaneboronate (a) and $\xi$-Epi-23-dehydrobrassinolide Bismethaneboronates $\mathrm{A}(\mathrm{b})$ and $\mathrm{B}(\mathrm{c})$.

nation revealed four peaks at $11.45,12.70,13.85$, and $14.43 \mathrm{~min}$ (Table II). The relative intensities of these peaks were 3:50:4:1. We could not detect the first peak in bismethaneboronates of the natural compounds. However, the relative retention times of the last three peaks $(100,109$ and 114) coincide with those obtained from the natural compounds (Tables I and II). Furthermore, the mass spectra of the former two and the latter two were identical to those of derivatives A and B of the natural products, respectively (Tables I and II). These data verify the proposed structures for compounds $\mathbf{4 , 5}$,

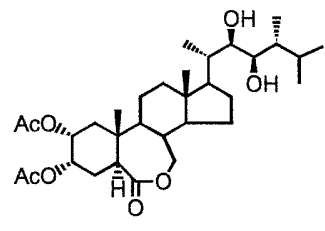

12

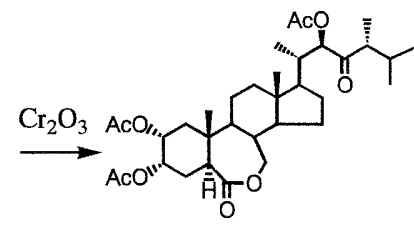

14
13

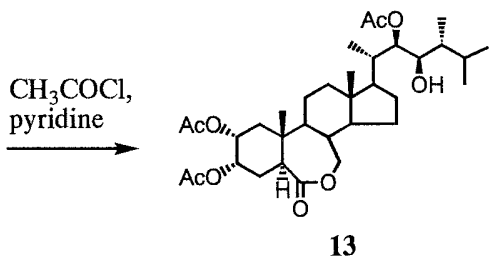

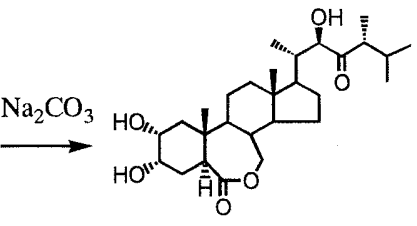

15
Fig. 6. Synthesis of 24-Epi-23-dehydrobrassinolide (15).

6 and 7. However, the retention times of the 15 bismethaneboronates do not match those of the natural compounds, leaving the stereochemistry of all the compounds undetermined.

\section{Discussion}

The present study demonstrates the uniqueness of $C$. japonica in its pollen and anthers containing a variety of BRs with either a 24-methyl ( $\left.\mathrm{C}_{28} \mathrm{BRs}\right)$, 24-methylene ( $\left.\mathrm{C}_{28} \mathrm{BRs}\right)$, 24-ethyl ( $\left.\mathrm{C}_{29} \mathrm{BRs}\right)$ or 24-ethylidene $\left(\mathrm{C}_{29} \mathrm{BRs}\right)$. In contrast, in the pollen of other conifers, $P$. thunber$g i i^{19)}$ and $C$. arizonica, ${ }^{20)} \mathrm{C}_{28} \mathrm{BRs}$ having a $24 S$-methyl are predominant. It is interesting that $C$. japonicum accumulates epimeric mixtures of 23-dehydrobrassinolide (4, 5, 6 and 7), 28-homobrassinolide (8, 9 and 10) and 28-homodolicholide (11), although no epimer was detected with respect to 3-dehydroteasterone (1), typhasterol (2) or dolicholide (3). Among these, 23-dehydrobrassinolide epimers 4 and 7 and 28-homobrassinolide epimers $\mathbf{8}$ and $\mathbf{1 0}$ were quantitatively major BRs as judged by GC-MS (data not shown).

Epimerization of the $2 \alpha$ - and $3 \alpha$-hydroxyls in the $\mathrm{A}$ ring of BRs is known as deactivation metabolism. Epimers of castasterone and 25-methyldolichosterone, which have $2 \alpha, 3 \beta-, 2 \beta, 3 \alpha$ - or $2 \beta, 3 \beta$-hydroxyls, have been identified from seeds of Phaseolus vulgaris. ${ }^{24)}$ Furthermore, metabolites with $2 \alpha, 3 \beta$ - or $2 \beta, 3 \alpha$-hydroxyls have been found in the feeds of castasterone, 24epicastasterone and 24-epibrassinolide to cultured cells or seedlings of some plants. ${ }^{25-28)}$ Thus, it is likely that the

Table II. GC-MS Data on the Bismethaneboronates of Synthetic 24-Epi-23-dehydrobrassinolide (15)

\begin{tabular}{lll}
\hline $\begin{array}{l}\text { GC-tR } \\
(\mathrm{min})\end{array}$ & Prominent ions (relative intensity) & Assigned structure \\
\hline 11.45 & $526\left(\mathrm{M}^{+}, 25\right), 483(100), 429(11), 369(3), 355(13)$, & Bismethaneboronate A (Fig. 3) \\
& $343(4), 295(4), 281(6), 221(14), 207(6), 181(76)$, & \\
& $165(6), 147(26), 139(60), 125(17), 111(52)$ & Bismethaneboronate A (Fig. 3) \\
12.70 & $526\left(\mathrm{M}^{+}, 24\right), 483(100), 181(92), 165(11), 149(12)$, & Bismethaneboronate B (Fig. 3) \\
& $139(44), 129(19), 111(41)$ & \\
& $526\left(\mathrm{M}^{+}, 17\right), 483(13), 455(4), 373(11), 345(7)$, & Bismethaneboronate B (Fig. 3) \\
& $221(21), 207(11), 177(11), 163(12), 153(100)$, & \\
& $137(29), 121(11), 111(24)$ & \\
& $526\left(\mathrm{M}^{+}, 4\right), 374(3), 177(2), 153(100), 137(2)$, & \\
& $121(2), 111(6)$ &
\end{tabular}


Table III. Biological Activity of 24-Epibrassinolide and 24-Epi-23-dehydrobrassinolide (15) in the Rice Lamina Inclination Assay

\begin{tabular}{ccc}
\hline & \multicolumn{2}{c}{ Rice lamina angle (degrees \pm S.E., $\mathrm{n}=20)$} \\
\cline { 2 - 3 } Cencentration $(\mathrm{ppm})$ & 24-Epibrassinolide & 24-Epi-23-dehydrobrassinolide (15) \\
\hline 0.0001 & $45.2 \pm 4.2$ & $49.9 \pm 6.2$ \\
0.001 & $65.8 \pm 8.8$ & $50.5 \pm 4.5$ \\
0.01 & $92.7 \pm 9.8$ & $65.6 \pm 8.0$ \\
0.1 & $139.4 \pm 5.7$ & $112.1 \pm 5.9$ \\
1 & $144.6 \pm 5.7$ & $145.3 \pm 5.7$ \\
\hline Control & $42.6 \pm 4.4$ & \\
\hline
\end{tabular}

epimers of 23-dehydrobrassinolide $(4,5,6$ and 7$), 28$ homobrassinolide (8, 9 and 10) and 28-homodolicholide (11) in C. japonica had epimerized hydroxyl(s) in the Aring. Further elaboration of the structures of these isomers necessitates an extensive synthetic approach which is currently being undertaken.

The identification of epimeric mixtures of 23-dehydrobrassinolide first indicated that oxidation of the 23-hydroxyl (23-dehydrogenation) occurs in the metabolism of brassinolide and/or its epimers. 24-Epi23-dehydrobrassinolide was four-to ten-fold less potent than 24-epibrassinolide in the rice lamina inclination assay (Table III), suggesting that 23-dehydrogenation is a deactivation process. However, the results of the present study suggest that no 23-dehydrogenation occurs with respect to BRs other than brassinolide and its epimer in $C$. japonica. Furthermore, nothing has been reported about the oxidation of the 23-hydroxyl in the feeds of 24-epicastasterone and 24-epibrassinolide to cell suspension cultures of tomato and Ornithopus sati$v u s$, although varied structural changes occured to their side chains, including hydroxylation at C20, C25 and $\mathrm{C} 26$, and cleavage of the $\mathrm{C} 20-\mathrm{C} 22$ bond after $\mathrm{C} 20$ hydroxylation. ${ }^{27,28)}$ Therefore, it is likely that the enzyme responsible for 23-dehydrogenation may specifically utilize brassinolide. Thus, the enzyme may favor a side chain structure with a $24 S$-methyl, but not those with either a 24R-methyl (24-epi), 24-ethyl, 24-methylene or 24-ethylidene group. Although brassinolide was not detected in $C$. japonica, it must be endogenous because of the presence of 3-dehydroteasterone, as well as of typhasterol, a biosynthetic precursor of brassinolide. ${ }^{29,30)}$ Accordingly, in C. japonica, brassinolide may be extensively metabolized by oxidation of the 23hydroxyl and by epimerization of the A-ring hydroxyls.

Thus, it is concluded that epimerization and 23-dehydrogenation are important to the deactivation process of BRs in C. japonica.

\section{Acknowledgments}

The authors thank Masahito Muramatsu, Rieko Okegawa, Yoshie Ohya, and Junko Inaba of Joetsu University of Education for their help in collecting the plant material.

\section{References}

1) V. Marquardt and G. Adam, in "Chemistry of Plant Protection," ed. by W. Ebing, Springer, Heidelberg, 1991, pp. 103139.
2) A. Sakurai and S. Fujioka, Plant Growth Regul., 13, 147-159 (1993).

3) S. Takatsuto, J. Chromatogr., 658, 3-15 (1994).

4) J. M. Sasse, Physiol. Plant., 100, 696-701 (1997).

5) H. Suzuki, T. Inoue, S. Fujioka, T. Saito, S. Takatsuto, T. Yokota, N. Murofushi, and A. Sakurai, Phytochemistry, 42, 1391-1397 (1995).

6) Y.-H. Choi, S. Fujioka, T. Nomura, A. Harada, T. Yokota, S. Takatsuto, and A. Sakurai, Phytochemistry, 44, 609-613 (1996).

7) S. Fujioka and A. Sakurai, Physiol. Plant., 100, 710-715 (1997).

8) A. Sakurai and S. Fujioka, Biosci. Biotech. Biochem., 61, 757762 (1997).

9) J. Li, P. Nagpal, V. Vitart, T. C. McMorris, and J. Chory, Science, 272, 398-401 (1996).

10) M. Szekeres, K. Németh, Z. Koncz-Kélmån, J, Mathur, A. Kauschmann, T. Altmann, G. P. Rédei, F. Nagy, J. Schell, and C. Koncz, Cell, 85, 171-182 (1996).

11) S. D. Clouse, M. Langford, and T. C. McMorris, Plant Physiol., 111, 671-678 (1996).

12) A. Kauschmann, A. Jessop, C. Koncz, M. Szekeres, L. Willmitzer, and T. Altmann, Plant J., 9, 701-713 (1996).

13) T. Nomura, M. Nakayama, J. B. Reid, Y. Takeuchi, and T. Yokota, Plant Physiol. 113, 31-37 (1997).

14) S. D. Clouse, Physiol. Plant., 100, 702-709 (1997).

15) S. Fujioka and A. Sakurai, Nat. Prod. Rep., 14, 1-10, 1997.

16) T. Yokota, Trend Plant Sci., 2, 137-143 (1997).

17) F. R. Hewitt, T. J. Hough, P. O'Neill, J. M. Sasse, E. G. Williams, and K. S. Rowan, Aust J. Plant Physiol., 12, 201-211 (1985).

18) M. D. Grove, G. F. Spencer, W. K. Rohwedder, N. Mandava, J. F. Worley, J. D. Warthen, G. L. Steffens, J. Flippen-Anderson, and J. C. Cook Jr., Nature. 281, 216-217 (1979).

19) T. Yokota, M. Arima, N. Takahashi, S. Takatsuto, N. Ikekawa, and T. Takematsu, Agric. Biol. Chem., 47, 2419-2420 (1983).

20) P. G. Griffiths, J. M. Sasse, T. Yokota, and D. W. Cameron, Biosci. Biotech. Biochem., 59, 956-959 (1995).

21) T. Yokota, T. Matsuoka, T. Koarai, and M. Nakayama, Phytochemistry, 42, 509-511 (1996).

22) S. Takatsuto, M. Muramatsu, Y. Ohya, S. Hayashi, and A. Shida, Agric. Biol. Chem., 52, 2059-2064 (1988).

23) S. Takatsuto, B. Ying, M. Morisaki, and N. Ikekawa, J. Chromatogr., 239, 233-241 (1982).

24) S.-K. Kim, in "Brassinosteroids. Chemistry, Bioactivity and Applications," ed. by H. G. Cutler, T. Yokota, and G. Adam, American Chemical Society, 1991, pp. 26-35.

25) H. Suzuki, S. Fujioka, S. Takatsuto, T. Yokota, N. Murofushi, and A. Sakurai, Biosci. Biotech. Biochem., 59, 168-172 (1995).

26) N. Nishikawa, H. Abe, M. Natsume, A. Shida, and S. Toyama, J. Plant Physiol., 47, 294-300 (1995).

27) T. Hai, B. Schneider, A. Porzel, and G. Adam, Phytochemistry, 41, 197-201 (1996).

28) A. Kolbe, B. Schneider, A. Porzel, and G. Adam, Phytochemistry, 41, 163-167 (1966).

29) H. Suzuki, T. Inoue, S. Fujioka, S. Takatsuto, T. Yanagisawa, T. Yokota, N. Murofushi, and A. Sakurai, Biosci. Biotech. Biochem., 58, 1186-1188 (1994).

30) H. Suzuki, S. Fujioka, S. Takatsuto, T. Yokota, N. Murofushi, and A. Sakurai, J. Plant Growth Regul., 13, 21-26 (1994). 